\title{
AC 2007-1470: CURRICULUM ENHANCEMENT TO PROMOTE ENVIRONMENTAL AWARENESS AMONG ENGINEERS
}

\section{Graham Armitage, University of Calgary}

Graham is a second year engineering student in Civil Engineering and has a Biological Sciences degree. He is a student member of EWB and is pursuing a specialization in Environmental Engineering.

\section{Phillip du Plessix, University of Calgary}

Phil is a second year Geomatics Engineering student who is specializiing in Biomedical Engineering. Phil haas work as a lifeguard and his summer work was supported by a Summer Research Award.

\section{Kara Chomistek, University of Calgary}

Kara is a second year Mechanical Engineering student who is specializing in Biomedical Engineering. Kara has volunteered with childern with disabilities at the Gorden Townsend School, part of the Alberta Childrens Hospital.

\section{Daryl Caswell, University of Calgary}

Daryl CASWELL is a professional Engineer, professional Musician and a Designer and Manufacturer of tools for the music industry. He has thirty years of experience as a teacher in engineering and music. Dr. Caswell also uses his multi-disciplinary background in the field of acoustics as well as in design and engineering education.

\section{Clifton Johnston, University of Calgary}

Clifton has work as a Professional Engineer in the Aerospace, Oil \& Gas, Municipal and Biomedical industries. He has taught design at the University of Calgary for the past 7 years, while continuing his research in Biofluids, sports engineering and design methodology and teaching.

\author{
Mohamed Nazir, University of Calgary \\ Marjan Eggermont, University of Calgary \\ Diane Douglas, University of Calgary \\ Brigit Knecht, University of Calgary
}




\section{Curriculum Enhancement to Promote Environmental Awareness among Engineers}

\section{Introduction}

The University of Calgary Schulich School of Engineering has introduced a set of first year design projects aimed at preparing engineering students to be both technically capable and conscious of the impacts of their decisions. The goal is to address the need for today's engineers to work effectively in global environments where technical solutions must integrate social, cultural and environmental concerns.

The curriculum enhancement projects seek to teach the students the fundamentals of engineering design early (first three weeks) in the engineering education process with an emphasis on environmental and socio-cultural impact to develop socially conscious engineers with a strong grounding in the basics of engineers design methods. This will develop a new generation of engineers with a skill set that includes an understanding of the social, cultural and environmental impacts of their decisions and a comprehension of how these concepts are firmly ingrained in the creative problem solving process.

The curriculum enhancement projects also seek to quantitatively and qualitatively measure the student's retention, enthusiasm and knowledge of the subject as a short term longitudinal study (4 months). This has been accomplished by providing the students with a small set of open-ended questions at the completion of the design projects.

\section{Engineering and the social, cultural, and environmental considerations}

Course coordinators for the first-year engineering design program at the University of Calgary ( $\mathrm{U}$ of $\mathrm{C}$ ) believe that by introducing problem solving techniques early in the engineering education process students will be influenced throughout their careers. This is critical as students are shaped by the behaviors of their engineering educators in both their approach to design, and integration with the environment ${ }^{4,5}$. Introducing problem solving together with social and cultural awareness is particularly important as engineers are increasingly employed by large multinational corporations ${ }^{3}$. Thus there is a need for engineers who can interact with the public worldwide as well as provide the most appropriate solution ${ }^{8,3}$. Engineering students discover too soon that the roots of a problem are often much broader than the perceived problem. Providing an appropriate solution is very challenging and requires engineers who are guided by their "ethics and are able to bridge the gaps between cultures and between people and technology".

The $\mathrm{U}$ of $\mathrm{C}$ has implemented this new curriculum enhancement in conjunction with EWB to create engineers who will have "the ability to integrate widely separate areas of knowledge, as environmental problems are rarely one dimensional" " ${ }^{1}$. This is important because in the last 50 years there has been a shift which is reshaping the engineering profession. Engineers now must be "responsible stewards rather than negligent trustees of the environment" 8 . Instead of being seen "both as problem-causers and problem-solvers," as said by J. M. N. Van Kasteren. 
engineers without borders background:

In Canada, Engineers Without Borders (EWB) appeared on the engineering education front in the 1990's. The following quote from the EWB website explains their philosophy:

Poverty is not about weakness. For the 800 million people who go hungry each day and the one billion who lack access to clean water, poverty is an absence of opportunity. Engineers Without Borders is responding to this urgent need, helping people in developing communities gain access to technologies that will improve their lives. We believe that technology, when appropriately incorporated into each community's social, cultural, economic and political context, can drive extraordinary change.

The focus of EWB is on developing the technical capacity at the local level in developing countries to ensure that innovative, appropriate and sustainable solutions to issues that impede development are generated and available at that local level. Overseas projects cover three problem areas: water and sanitation, food processing, and rural energy.

The work of EWB is carried out at the local, national and international level, and has included projects in 27 countries. On Canadian soil, University chapters are the heart and soul of EWB with a mailing list of over 18000 and over 7000 regular and associate members, $75 \%$ of which are students. Three hundred and fifty executive volunteer members carry out administration. Local Canadian operations encompass high school outreach programs, curriculum enhancement, public outreach and member education.

\section{Engineering Design Program}

The Schulich School of Engineering offers a full-year, open-ended, real-world design course to all 750 first-year engineering students. These students are introduced to Familiarization, Functionality, and Testing design methodology ${ }^{9}$ while working on real-world design problems ranging in duration from two weeks to eight weeks. Our focus is on environmentally and socially conscious design, which ranges from aids for assisted living to EWB. The first-year design program aims to develop design, written and oral communication, visual communication and teamwork skills in all students. This course utilizes multidisciplinary instruction, bringing engineers from all disciplines, writers and artists together to develop and present the curriculum. Students spend $80 \%$ of their time working in dedicated design studios on projects. The foundation of the student learning is inquiry-based and project driven. It is within this framework that our EWB projects are run.

\section{History of EWB at the University of Calgary}

Beginning in 2002, the student chapter of EWB, working with the course instructors, has developed and delivered design projects that range from two to six weeks in duration. All EWB projects have the same focus: to bring undergraduate engineering students to the realization that the role of the engineer is expanding from simply creating solutions to creating solutions that address the social, cultural and environmental aspects of problems that originate in countries, civilizations and environments that are entirely foreign to most engineering students. 
To generate appropriate solutions requires students to become engineers that are not only technically capable, but also conscious of the social, and physical environment in which they are working. The common goal of EWB and the first year design course is to develop a generation of engineers who understand the social dynamics of technology 6 .

At the University of ? we believe that, the Curriculum Enhancement Program has the greatest potential to create sustainable behaviour change within the engineering profession, and allows for variability of projects. The program introduces the following concepts to engineering students: ${ }^{2}$

1. Appropriate technology - All technology should match its particular context in terms of cost, scale, technical complexity, sustainability, cultural acceptability and level of ownership.

2. Human Development - International development is about people, not projects

3. Social Responsibility - Engineers have a moral responsibility to help society

This is entirely complementary to the first year design course, which is focused on providing students with real world, unsolved design problems that also promote social and cultural awareness.

\section{Project Descriptions}

\section{Irrigation and you}

"Irrigation and You" was designed to focus student's attention on the importance of conceptualization in design. Successful groups produced functional irrigation system by doing research into the current types of irrigation systems in use, the availability of water in the region, and the users of the system. Project success was determined based on the completeness of a written assignment which required students to show the research and justification used to complete the project.

In groups of four, the students were provided with a small sample of materials including; paperclips, elastic bands, paper, straws, staples and tape. The materials were chosen because they are commonly found and of low cost (total cost $\sim 100$ for 750 students). The students were then provided with a project description, to create an irrigation system for a plot of land $(1 \mathrm{~m} \mathrm{x} 1 \mathrm{~m})$ representative of a small plot of land used by rural farmers in a Village in Africa. Students were given two laboratory sessions (4 hours), over 2-5 days to complete the project and encouraged to research the environmental, social, and cultural characteristics of the region which their group was assigned (eg. Ghana, Zimbawae, Burkina Faso).

\section{Food for thought}

Throughout the entire "Food For Thought" project students were utilizing all the fundamentals of engineering design (Conceptualization, Evaluation, Testing, and Redesign). This project proved to be extremely challenging for students given the time allotted for the project ( 8 hrs, over 4 lab sessions). 
This project was created by building upon a similar program for high school students to be used in the High School Outreach Program (HSO). The same principals were used and the content was enhanced to be more appropriate for this design course.

This project required students to:

1. Determine a technique they believe is the most appropriate to husk rice according to their own research into the process.

2. Create a process for husking rice using the provided materials

a. 12in length of $2 \times 4$, with a $1 / 2$ inch groove

b. 12 in $x 6$ in length of $1 / 2$ plywood

c. 1 plastic fork

d. $2 \frac{1}{2}$ strips of sand paper

e. $6 x 6$ in square of wire mesh

f. 2in length of 3 in diameter plastic tubing

g. 2 varied lengths of scrap metal

h. 1 balloon

3. Prove that the technique created is an effective method of husking rice, and modify the process if redesign was necessary

4. Determine a method of mechanically husking rice, using the knowledge of rice processing they have learned.

\section{Project outcomes}

To determine the success of the new EWB curriculum enhancement projects ("Irrigation and You", and "Food for Thought") a questionnaire was created by University of ? EWB members and project coordinators. The questionnaire consisted of eleven open ended questions designed to determine three main issues:

1. The knowledge students had learned about the fundamentals of engineering design

2. Level of knowledge students had about the social, cultural and environmental issues that are prevalent in engineering

3. If students were learning information related to international development though their research and from presenters

When analyzing the responses of the questions related to issue $1,37.89 \%$ of the respondents found that conceptualization influenced the method of rice processing, and are shown Table 1. 


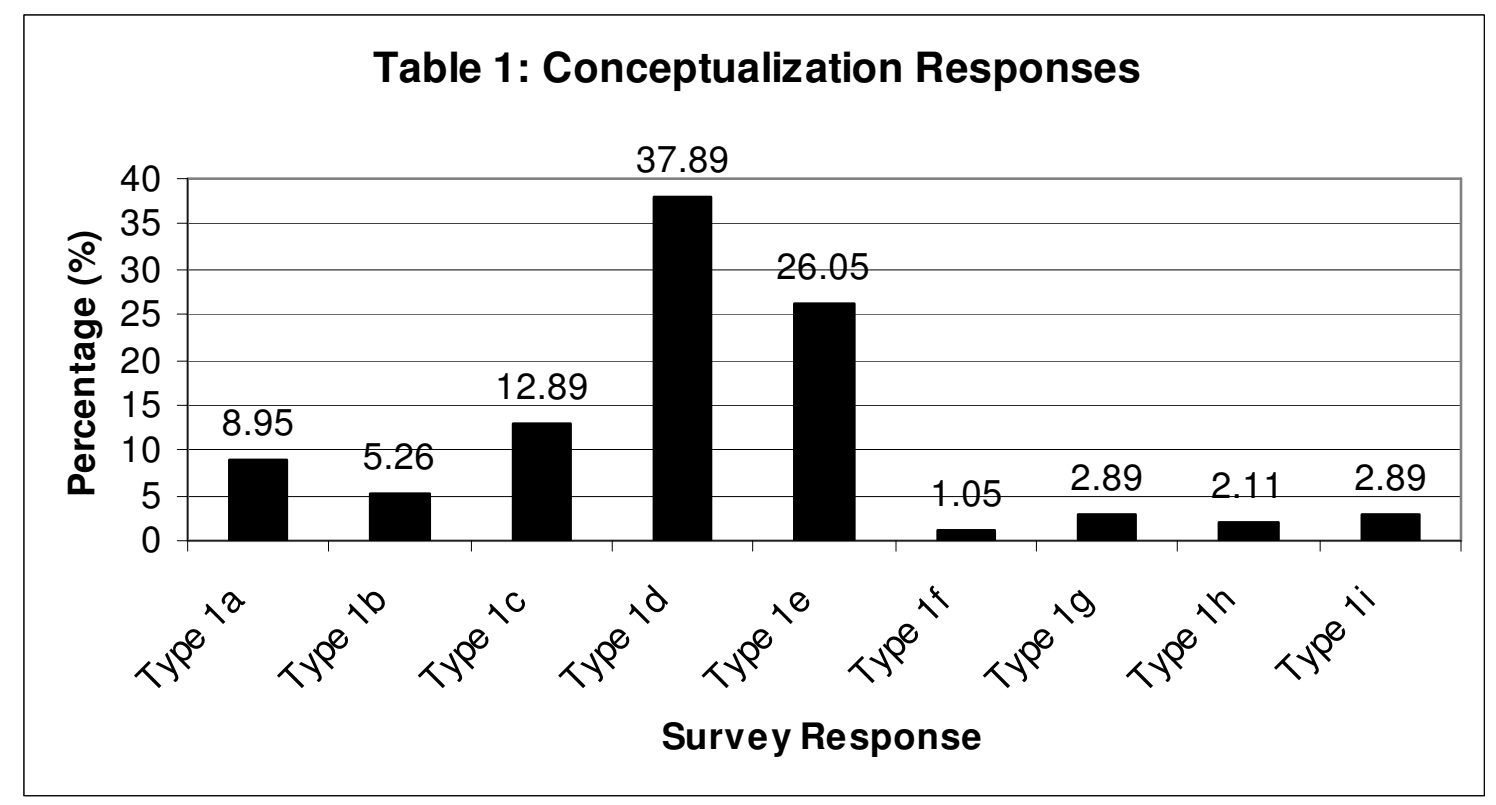

key to Table 1:

\begin{tabular}{|ll|}
\hline Type 1a & Helped to determine how to start the project \\
Type 1b & Helped to identify the appropriate materials \\
Type 1c & Brought attention to how culture can affect the design \\
Type 1d & Helped to determine different methods to process rice \\
Type 1e & Helped to gain a general knowledge of rice and rice husking \\
Type $1 \mathrm{f}$ & It was unhelpful \\
Type $1 \mathrm{~g}$ & Question misunderstood \\
Type 1h & Incomplete response \\
Type 1i & Question not answered \\
\hline
\end{tabular}

When analyzing the responses of the questionnaire related to conceptualization; there was a more even distribution as shown in Table 2. 


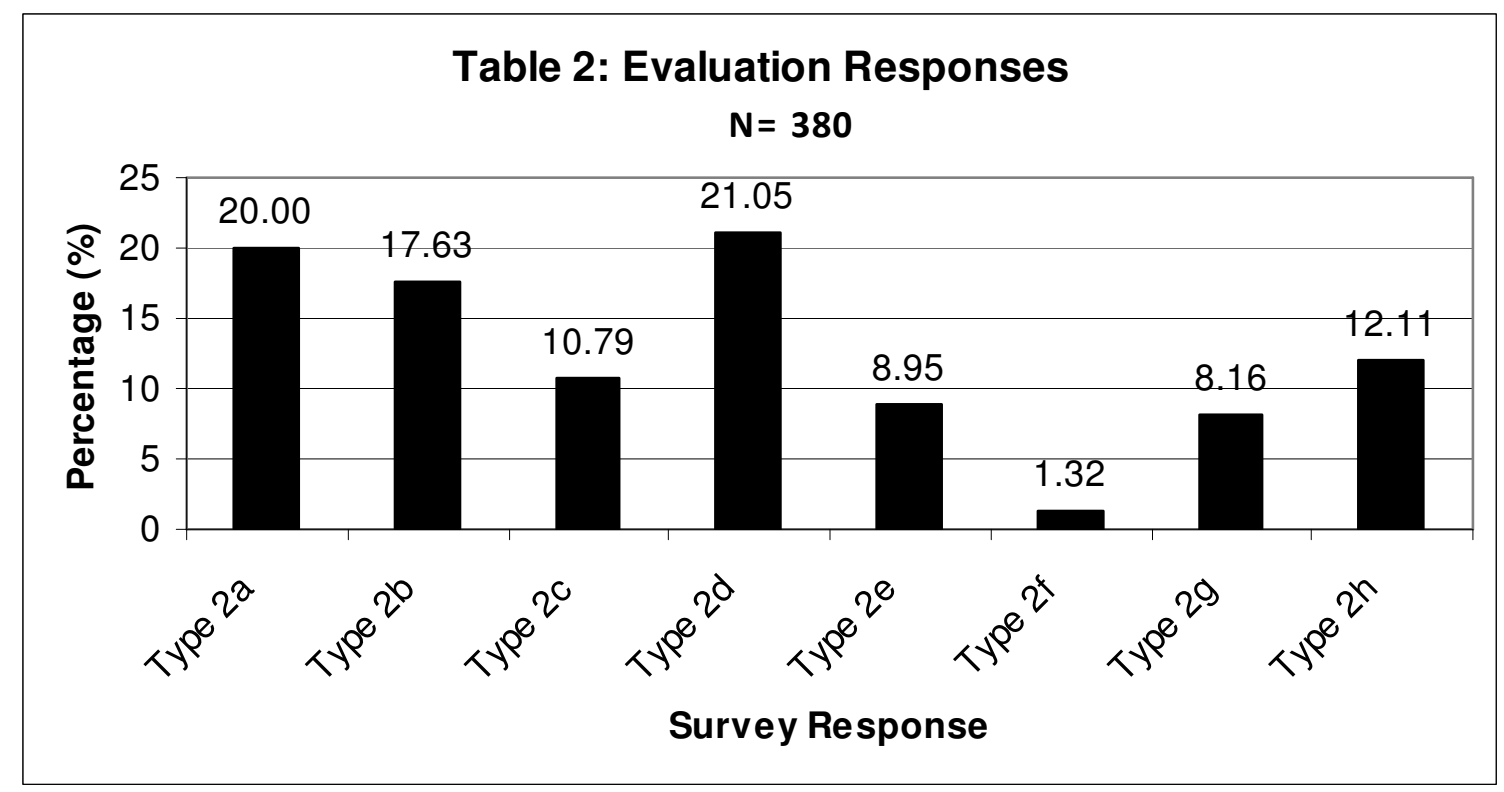

key to Table 2:

\begin{tabular}{|ll|}
\hline Type $2 \mathrm{a}$ & Information on how husking worked \\
Type $2 \mathrm{~b}$ & Methods \\
Type $2 \mathrm{c}$ & Materials \\
Type $2 \mathrm{~d}$ & Design \\
Type $2 \mathrm{e}$ & Process \\
Type $2 \mathrm{f}$ & Culture \\
Type $2 \mathrm{~g}$ & Question misunderstood \\
Type $2 \mathrm{~h}$ & Question not answered \\
\hline
\end{tabular}

When analyzing the responses related to testing students expressed that it had the largest influence on the rice husking design, as shown in Table 3. 


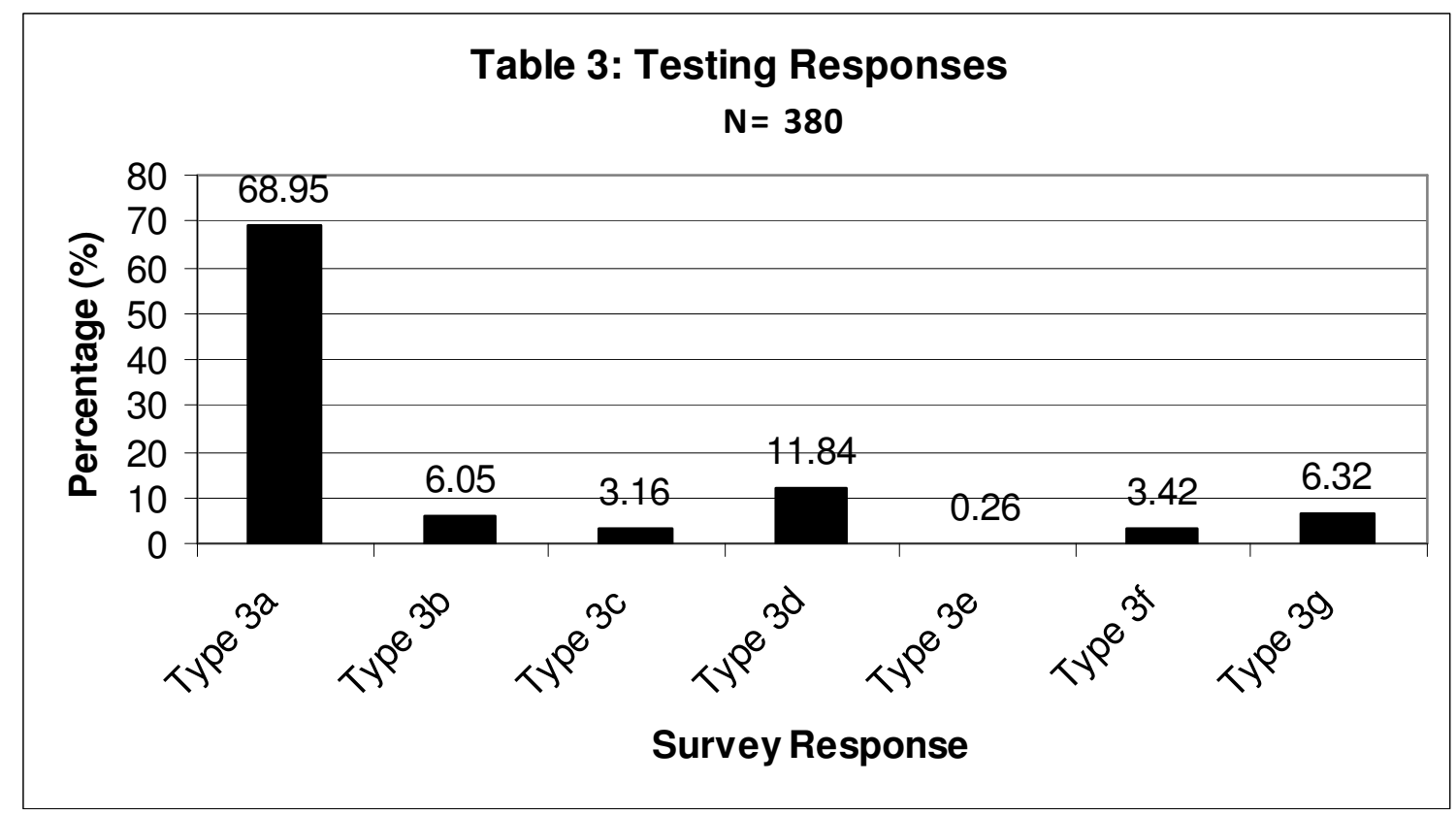

key to Table 3:

\begin{tabular}{|ll|}
\hline Type $3 a$ & Influenced the design changes \\
Type $3 b$ & Influenced further familiarization, and functionality \\
Type $3 c$ & Influenced the materials \\
Type $3 d$ & Influenced the testing process \\
Type $3 e$ & Did not help \\
Type $3 f$ & Question misunderstood \\
Type $3 g$ & Question not answered \\
\hline
\end{tabular}

When analyzing the data related the issue 2, the level of knowledge students had about the social, cultural and environmental issues, it was determined that the questions given to the students elicited biased responses and therefore the data is not statistically viable. However, a random selection of responses did indicate that students do believe that social and cultural issues are important in engineering design and are illustrated by the following randomly selected quotes.

"they are important in life and engineering helps facilitate life"

"engineering is building for society"

"projects must be designed for different societies and cultures"

"because if the solution does not fit to society and cultural norms it won't fly"

"depending on the cultures different methods of working and work partitioning can play a role in the overall decision process" 
When analyzing the data related to issue 3 , if students were learning information related to international development, it can be shown that of the sample population, $45.79 \%$ of the students knew little to nothing prior to the start of the project and after completion felt that they had increased their knowledge of the subject area (Table 4).

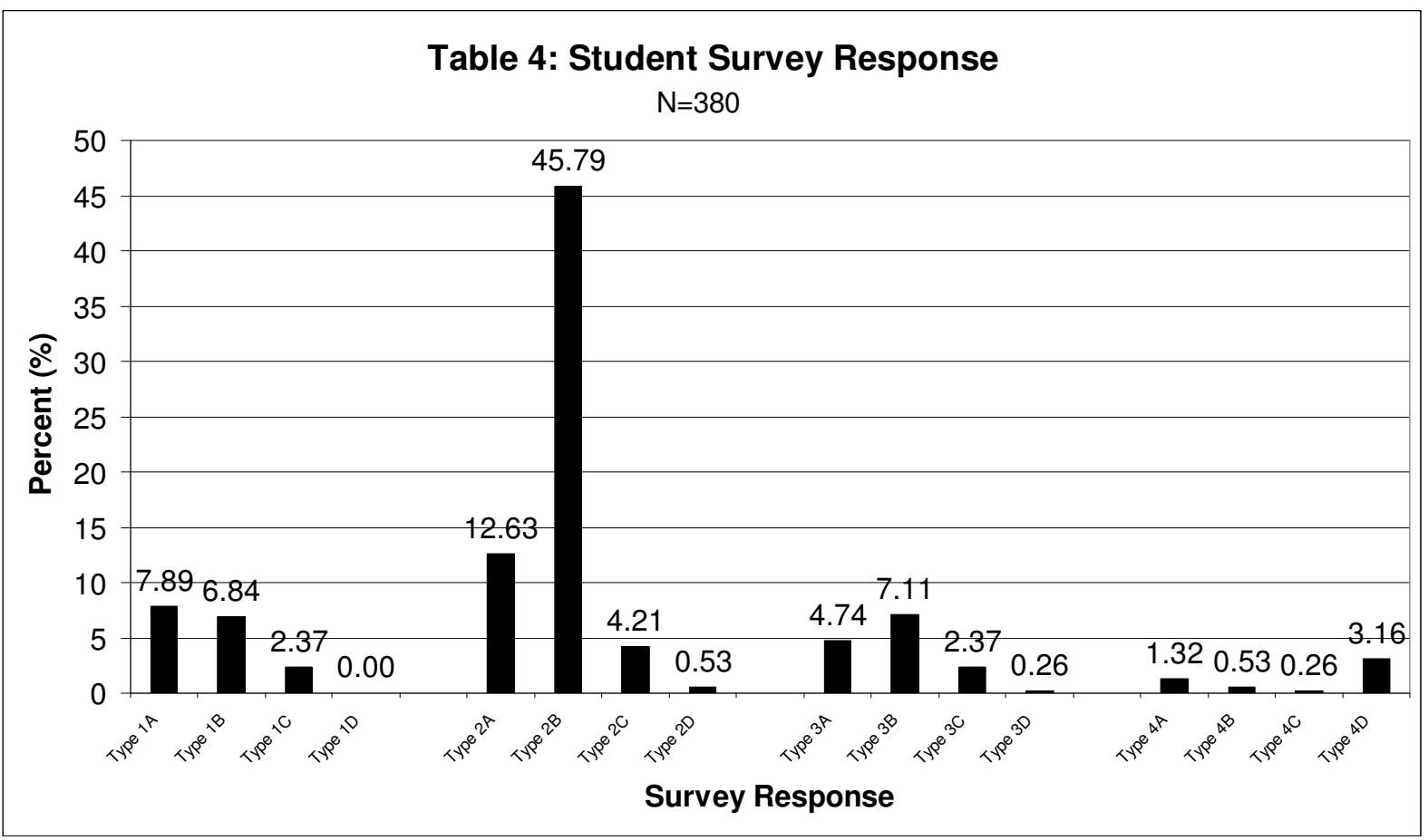


key to Table 4:

\begin{tabular}{|ll|}
\hline Type 1A & Did not answer part 1, Did not answer part 2 \\
Type 1B & Did not answer part 1, More informed after projects \\
Type 1C & Did not answer part 1, Less informed after projects \\
Type 1D & Did not answer part 1, Misunderstood part 2 \\
Type 2A & Knew nothing before, Did not answer part 2 \\
Type 2B & Knew nothing before, More informed after projects \\
Type 2C & Knew nothing before, Less informed after projects \\
Type 2D & Knew nothing before, Misunderstood part 2 \\
Type 3A & Knew something before, Did not answer part 2 \\
Type 3B & Knew something before, More informed after projects \\
Type 3C & Knew something before, Less informed after projects \\
Type 3D & Knew something before, Misunderstood part 2 \\
& \\
Type 4A & Misunderstood part 1, Did not answer part 2 \\
Type 4B & Misunderstood part 1, More informed after projects \\
Type 4C & Misunderstood part 1, Less informed after projects \\
Type 4D & Misunderstood part 1, Misunderstood part 2 \\
\end{tabular}

\section{Conclusions}

By utilizing the curriculum enhancement programs like those developed at the University of Calgary we can ensure that future generations of engineers are equipped to enter the international community with an understanding of the importance of the social, cultural and environmental implications of their projects. Based on the evidence presented, the first year engineering students enrolled in the Engineering Design and Communications course were introduced to fundamentals of engineering design (Conceptualization, Evaluation, Testing). Students also showed an understanding that the social, cultural, and environmental aspects of engineering are important to design. Lastly is was shown that over the three week EWB curriculum enhancement program approximately $70 \%$ of the students felt that they had improved their understanding of international development.

\section{Bibliography}

[1] Bhamidimarri, R. and Butler, K.,1998, "Environmental engineering education at the millennium: an integrated approach," Water Science and Technology, vol. 38, pp. 311-314.

[2] Engineers Without Borders [Executive Handbook], The Orange Book of Change: Bam! The guide to kickin it up a notch, 2006-2007. Available: 366 Adelaide Street West, Suite 601. Toronto, Ontario M5V 1R9. 
[3] Johnston. S. F., 2001, "Towards culturally inclusive global engineering?," European Journal of Engineering Education, vol. 26, pp. 77-89.

[4]Newcomer, J.L., 1997, A Broadened Prespective: Teaching Engineering Design in a Social Contect. American Society of Engineering Educators.

[5] Pritchard, J. and Baillie, C., 2006, "How Can Engineering education contribute to a sustainable future?" European Journal of Engineering Education vol31, No 5, pp 555-565.

[6] Ravesteijn, W., De Graaf, E. and Kroesen, O., 2006, "Engineering the Future: The Social Necessity of Communicative Engineers." European Journal of Engineering Education vol 31,N0.1 pp.63-71.

[7] Van Kasteren, J. M. N., 1996, "Interdisciplinary teaching within engineering education," European Journal of Engineering Education, vol. 21, p. 386.

[8] Wareham, D.G. and Elefsiniotis, P., 1996, "Environmental Ethics In Engineering Education: A Missing Fundamental," Water Science and Technology. vol. 34. No. 12 pp. 197-203.

[9] Caswell, D.J., Johnston, C.R., Douglas, D.M. and Eggermont, M.J. Fundamentals of a First-Year Engineering Design and Communication Course: Familiarization, Functionality and Testing. Proceeding of the 2004 American Society of Engineering Education Annual Conference and Exposition, Salt Lake City, Utah. June 2004. 